\title{
Lung evolution in vertebrates and the water-to-land transition
}

\author{
Camila Cupello $^{1 *}$, Tatsuya Hirasawa ${ }^{2}$, Norifumi Tatsumi ${ }^{3}$, Yoshitaka Yabumoto ${ }^{4}$, Pierre \\ Gueriau $^{5,6}$, Sumio Isogai ${ }^{7}$, Ryoko Matsumoto ${ }^{8}$, Toshiro Saruwatari ${ }^{9,10}$, Andrew King ${ }^{11}$, \\ Masato Hoshino ${ }^{12}$, Kentaro Uesugi ${ }^{12}$, Masataka Okabe ${ }^{3}$, Paulo M. Brito ${ }^{1 *}$
}

${ }^{1}$ Departamento de Zoologia-IBRAG, Universidade do Estado do Rio de Janeiro, R. São Francisco Xavier, 524-Maracanã, Rio de Janeiro 20550-900, Brazil._camila.dc@gmail.com; pbritopaleo@yahoo.com.br ${ }^{2}$ Department of Earth and Planetary Science, Graduate School of Science, The University of Tokyo 7-3-1 Hongo, Bunkyo-ku, Tokyo 113-0033, Japan. hirasawa@eps.s.u-tokyo.ac.jp ${ }^{3}$ Department of Anatomy, The Jikei University School of Medicine, 3-25-8 Nishi-Shimbashi, Minato-ku, Tokyo 105-8461, Japan.noratt2008@gmail.com; maokabe@jikei.ac.jp

${ }^{4}$ Kitakyushu Museum of Natural History and Human History, 2-4-1 Higashida, Yahatahigashi-ku, Kitakyushu, Fukuoka 805-0071, Japan. yabumoto@kmnh.jp ${ }^{5}$ Institute of Earth Sciences, University of Lausanne, Géopolis, 1015 Lausanne, Switzerland. pierre.gueriau@hotmail.fr ${ }^{6}$ Université Paris-Saclay, CNRS, ministère de la Culture, UVSQ, MNHN, Institut photonique d'analyse non-destructive européen des matériaux anciens, 91192 Saint-Aubin, France.

${ }^{7}$ Department of Anatomy, Iwate Medical University School of Medicine, Morioka, Iwate, Japan. sumio_isogai@yahoo.co.jp

${ }^{8}$ Kanagawa Prefectural Museum of Natural History, 499, Iryuda, Odawara, Kanagawa, 250-0031, Japan. ryokosaur@gmail.com

${ }^{9}$ Atmosphere and Ocean Research Institute, The University of Tokyo, Chiba, Japan. tsaruwat@ aori.utokyo.ac.jp

${ }^{10}$ Seikei Education and Research Center for Sustainable Development, Tokyo, Japan.

${ }^{11}$ Synchrotron SOLEIL, L'orme des Merisiers Saint-Aubin, BP48, F-91192, Gif-sur-Yvette Cedex, France. king@synchrotron-soleil.fr

${ }^{12}$ Japan Synchrotron Radiation Research Institute (JASRI/SPring-8), 1-1-1 Kouto, Sayo, Hyogo 679-5198, Japan. hoshino@spring8.or.jp; ueken@spring8.or.jp

*Corresponding authors. Email: camila.dc@gmail.com; pbritopaleo@yahoo.com.br

\section{Abstract}

A crucial evolutionary change in vertebrate history was the Palaeozoic (Devonian 400 million years ago) water-to-land transition, allowed by key morphological and physiological modifications including the acquisition of lungs. Nonetheless, the origin and early evolution of vertebrate lungs remain highly controversial, particularly whether the ancestral state was paired or unpaired. Due to the rarity of fossil soft tissue preservation, lung evolution can only be traced based on the extant phylogenetic bracket. Here we investigate, for the first time, lung morphology in extensive developmental series of key 
living lunged osteichthyans using synchrotron X-ray microtomography and histology. Our results shed light on the primitive state of vertebrate lungs as unpaired, evolving to be truly paired in the lineage towards the tetrapods. The water-to-land transition confronted profound physiological challenges and paired lungs were decisive for increasing the surface area and the pulmonary compliance and volume, especially during the airbreathing on land.

\section{Introduction}

Lungs, the most important organ of the pulmonary complex, are rarely preserved in fossils, hindering direct evidence of how the earliest air-breathing vertebrates breathed air. So far, the evolutionary origin of the vertebrate lung has been narrowed down to the basal osteichthyans (Goujet, 2011; Tatsumi et al., 2016). However, since the knowledge about morphological and genetic development of the lung has been highly biased in amniotes, the original form of this evolutionary novelty has remained elusive. One hypothesis, formed and supported by studies on tetrapods (particularly mammals and birds), assumes that the lung evolved through a modification of the pharyngeal pouch (Kastschenko, 1887), as the lung bud develops at the pharyngo-oesophageal junction during embryonic development. Consequently, this view (Kastschenko, 1887; Kuratani and Tanaka, 1990) predicts that the primitive lungs appeared as bilaterally paired organs at the caudolateral part of the pharynx. Indeed, in embryology, lungs of living tetrapods have been mostly described as paired derivates of the respiratory tube, arisen from paired and small hollow swellings (Marshall Flint, 1990). Previous studies on amphibians have also proposed that the lung bud develop from paired rudiments of the ventral portions of the eighth pharyngeal pouches (Goodrich, 1931; Marcus, 1937; Perry et al., 2001). Additionally, the 
plesiomorphic state of lungs has been mostly described as paired organs (Funk, Lencer and McCune, 2020). On the other hand, another hypothesis does not constrain the evolutionary origin of the lung to the serial homologue of the pharyngeal pouch (Greil, 1913; Neumayer, 1930; Wassnetzov, 1932). In this view, although the possibility that the primitive lung developed on the pharyngeal endoderm is not excluded, the primitive lung is considered to appear on the floor of the pharynx, or more generally, on the floor of the foregut. This scenario does not predict bilaterally paired forms of primitive lungs.

Curiously, some living vertebrates display an unpaired organ (Cupello et al., 2015;

Cupello et al., 2017a; Cupello et al., 2017b; Cupello, Clément and Brito, 2019; Lambertz and Perry, 2015; Lambertz et al., 2015), leaving the ancestral condition equivocal. The sister group to all other extant actinopterygians, the obligate air-breathing polypterids (Icardo et al., 2017), breath air using lungs, which have previously been described as a paired organ (Icardo et al., 2017; Geoffrey Saint Hilaire, 1802; Graham, 1997). However, in adult specimens of Polypterus senegalus the glottis only opens to the right sac and the left sac is connected to the right sac by a separate opening (Graham, 1997), raising old questions about its true paired condition. Among sarcopterygians, the unpaired lung of coelacanths is unequivocal. The living coelacanth Latimeria chalumnae, that inhabits moderate deep-water and makes gas exchanges only through gills, have an unpaired lung with no outline of a second bud at different developmental stages (Cupello et al., 2015; Cupello et al., 2017a; Cupello, Clément and Brito, 2019). In the extant sister group of all tetrapods (Amemiya et al., 2013), namely lungfishes, the three extant genera have lungs capable to uptake oxygen from the air. However, in the most basal one, the facultative airbreather Neoceratodus forsteri, the lung is described as unpaired (Greil, 1913; Graham, 1997; Grigg, 1965). In contrast with both South American and African lungfishes, the 
Lepidosirenoidea, that are obligated air-breathers and have a lung described as a ventral paired organ (16) like tetrapod lungs.

To follow lung evolutionary history in vertebrates, we analyzed primitive sequence of morphogenesis of lungs of key living osteichthyans (Figs. 1-6). Embryos, larvae, juveniles and adults of $P$. senegalus, $N$. forsteri, Lepidosiren paradoxa were examined. To compare the lung anatomy of osteichthyan fishes with tetrapods, we studied also an extensive developmental series of the living salamandrid Salamandra salamandra, from early and late larvae to juveniles before and after metamorphosis (Fig. 5). As salamanders are often considered to have retained plesiomorphic characteristics of tetrapod stance and locomotion (Pierce et al., 2020), we used them here also as a model for understanding lung evolution in tetrapods. Specimens of mentioned taxa were examined through x-ray microtomography, the unique effective non-invasive methodology to study their morphology and histology at a three-dimensional (sub) microscale. When possible, we proceeded also with dissections and the study of histological sections. We compare our results with the available information from the lung of fossil taxa, the coelacanths and salamanders (Cupello, Clément and Brito, 2019; Brito et al., 2010; Tissier, Rage and Laurin, 2017).

\section{Results}

\section{The lung development in Polypterus senegalus}

From our observations on embryos of 8.0, 8.5, 9.1 and $9.3 \mathrm{~mm}$ TL (total length), the lung anlage develops as a ventral unpaired and tubular depression of the respiratory pharynx (the posterior portion of the pharynx), surrounded by undifferentiated mesenchymal cells ${ }^{6}$ (Fig. 1A, B, Fig. 2B, C). Only at the $12 \mathrm{~mm}$ TL larva, the left bud arises from the principal 
and primary lung anlage as a branch (Fig. 2D). Subsequently, the lung assumes its asymmetrical morphology, the left sac is smaller and remains ventral in the abdominal cavity, while the right one (principal tube) starts a partial turn up and stays parallel to the dorsal portion of the foregut (including the stomach). The left sac keeps a secondary connection to a lateral opening of the principal tube, and not to the foregut (Fig. $1 \mathrm{D}, \mathrm{E}$, Fig. 6 A, B, Fig. S1, Fig. S2). Uundifferentiated dense cells surrounding the glottis are visible for the first time in specimens of $15.5 \mathrm{~mm}$ TL (black arrows in Fig. 2E). Airbreathing behavior starts at the juvenile stage in P. senegalus (2), and from juveniles of 23 mm TL onward, the blastema starts to develop into the muscular sphincter and respiratory epithelium at the glottis (ciliated cells intercalated by goblet cells). Right and left sacs are well developed and have a projection anterior to the connection with the small pneumatic duct in juveniles (Fig. 1D, E). The right tube is three times longer than the left one, with an expanded diameter in its caudal portion, posterior to the stomach (Fig. 1C, D). 


\section{posterior <----> anterior}
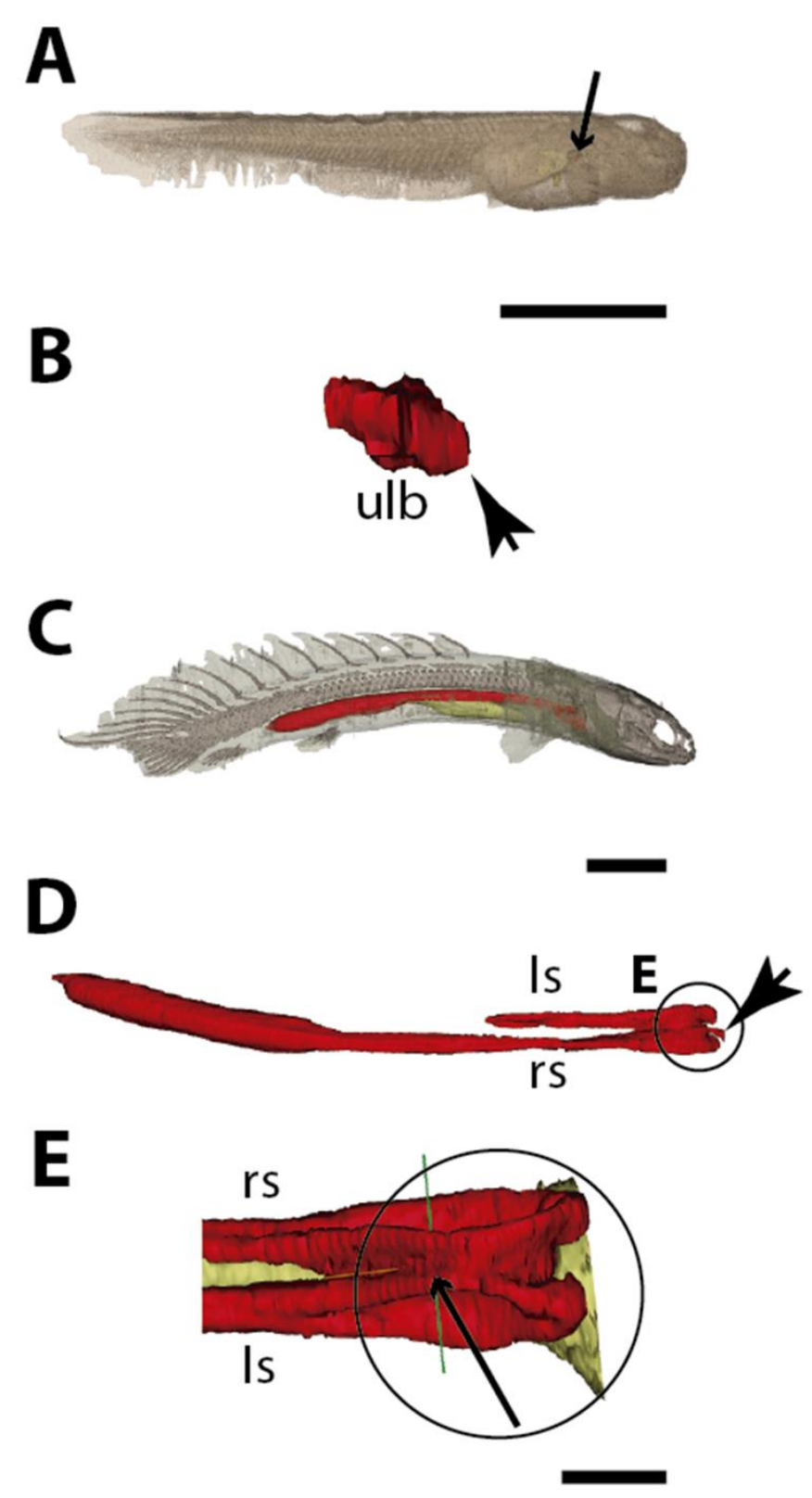

Fig. 1. Three-dimensional reconstructions of the pulmonary complex of Polypterus senegalus. (A) Early embryo $(9.3 \mathrm{~mm}) \mathrm{TL}$ in right lateral view, (B) Isolated lung of the early embryo in dorsal view, (C) Juvenile ( $45 \mathrm{~mm} \mathrm{TL}$ ) in right lateral view, (D) Isolated lung of the juvenile in dorsal view, (E) Close-up of (D) highlighting the lung in ventral view and pointing out the region of the independent and secondary connection of the left sac to the right one by a lateral opening. Yellow, foregut including the stomach; red, lung. Black arrow in (A) pointing to the lung. Arrowheads in (B) pointing to the lung connection to the foregut and in (D) pointing to the pneumatic duct connection to the foregut. Black arrow in (E) pointing to the independent connection. Ls, left sac; rs, right sac; ulb, unpaired lung bud. Scale bars, $5.0 \mathrm{~mm}(\mathbf{A}) ; 0.075 \mathrm{~mm}(\mathbf{B}) ; 5.0 \mathrm{~mm}(\mathbf{C}, \mathbf{D}) ; 1.0 \mathrm{~mm}(\mathbf{E})$. 
The right and left sacs make a partial turn-up, remaining parallel to the dorsal surface of the upper gastrointestinal tract (one of each side). Polypterus senegalus lung is internally smooth and lacks alveolation at all the examined developmental stages, except for in the $45 \mathrm{~mm}$ TL juvenile, in which the most anterior projection of the lung, anterior to the connection with the pneumatic duct, is slightly compartmentalized. This evidence based on the first developmental stages of $P$. senegalus (embryos with $8.5 \mathrm{~mm}, 9.1 \mathrm{~mm}$, $9.3 \mathrm{~mm}$ ) lung prove that the lung bud initially develops as an unpaired anlage in this taxon (Fig. 1B, Fig. 2 B, C). The left sac develops secondarily from the right sac at later developmental stages, as a diverticulum, or a lobe, of the right primary lung (Fig. 2 E, F, Fig. S1, Fig. S2). 

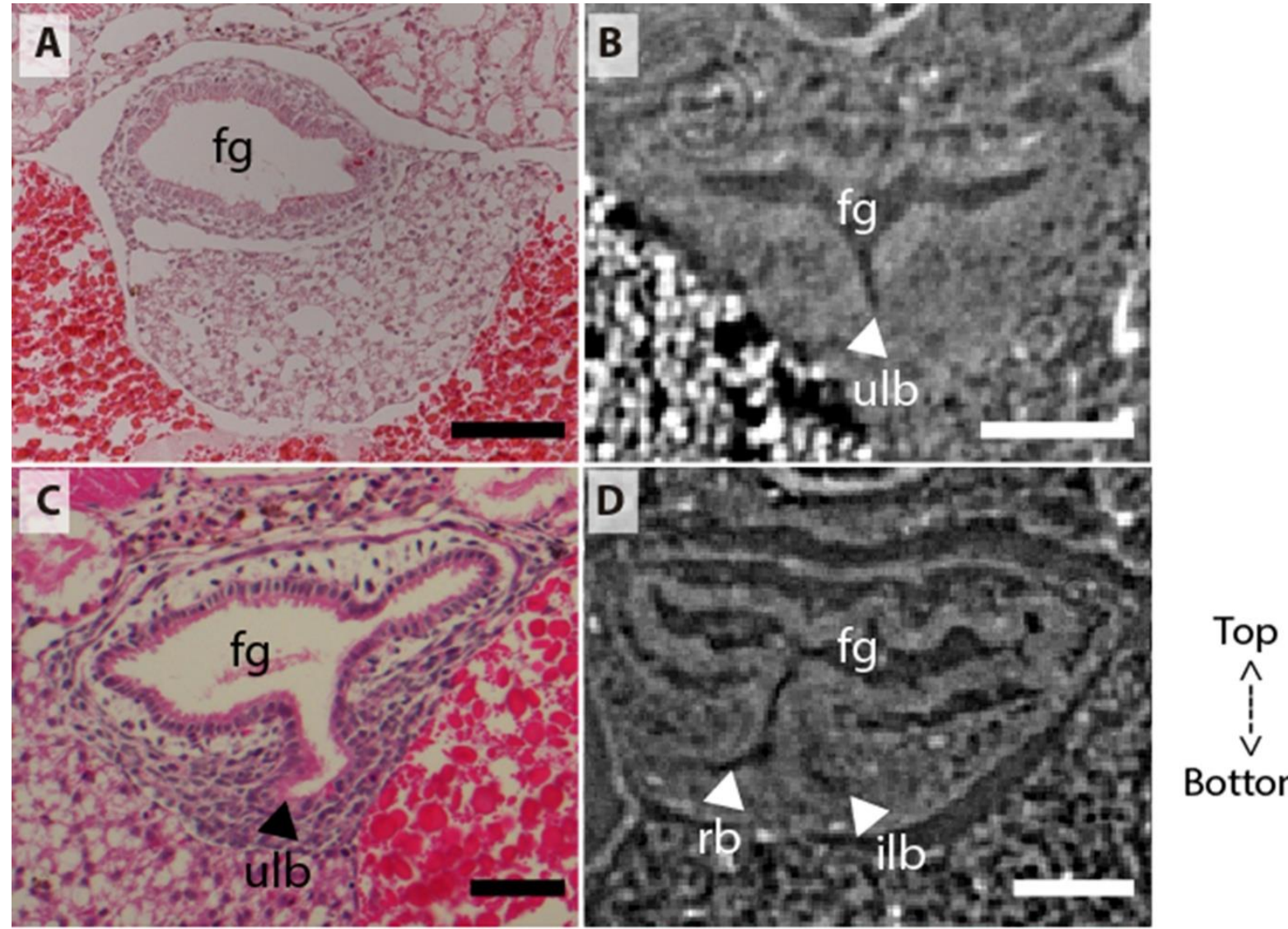

Bottom
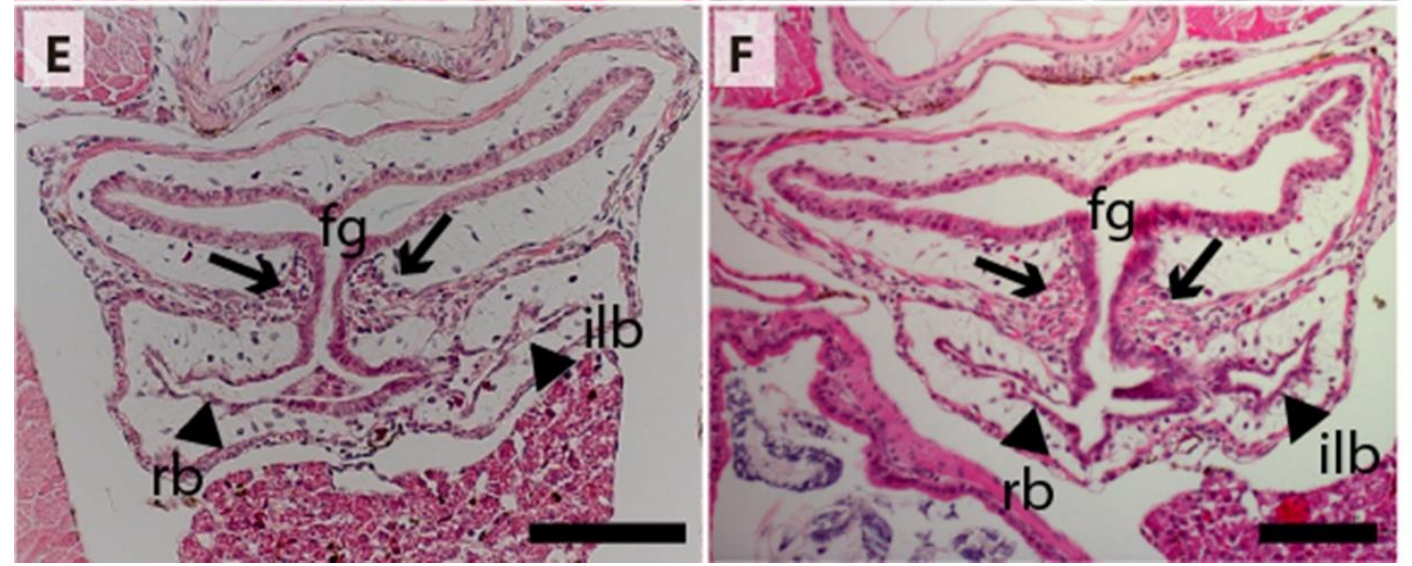

Fig. 2. Coronal sections of the unpaired lung in the living actinopterygian fish

Polypterus senegalus. (A) No lung bud in $8.0 \mathrm{~mm}$ TL specimen, (B) Origin of an unpaired lung bud in $8.5 \mathrm{~mm}$ TL specimen, (C) Unpaired lung bud in $9.1 \mathrm{~mm}$ TL specimen, (D) First register of an independent and lateral second lung bud in 12 mm TL specimen, (E, F) Independent and lateral second lung bud arising from the principal tube in $15.5 \mathrm{~mm}$ TL and $18 \mathrm{~mm}$ TL specimens. (A, C, E-F) Histological thin-sections. (B, D) Sections of synchrotron X-ray microtomography of the early embryo. Black and white head arrows pointing to the lumen of the unpaired lung buds; arrows pointing to the undifferentiated cells surrounding the glottis. Fg, foregut; ilb, independent lateral bud; rb, right bud; ulb, unpaired lung bud. Scale bars, $0.2 \mathrm{~mm}(\mathbf{A}, \mathbf{E}) ; 0.1 \mathrm{~mm}(\mathbf{B}, \mathbf{D}, \mathbf{F}) ; 0.05 \mathrm{~mm}(\mathbf{C})$. 


\section{The lung development in Latimeria chalumnae}

Embryos of L. chalumnae display ventral compartmentalized unpaired lung throughout its

length, suggesting alveolation (7), and in the early embryo (40 mm TL) a lateral and internal chamber is also present (Fig. 3; Fig. 6 D). At the latest developmental stages the pulmonary complex shows vestigial features, and no internal compartmentalization is recognizable (Lambertz and Perry, 2015). Adult specimens have constrictions and septations that divide the unpaired lung into separate lobes throughout its length, as in some fossil coelacanths (Cupello, Clément and Brito, 2019). Fossil coelacanths, from late

Devonian to late Cretaceous, were most probably facultative air-breathers and made gas exchanges through their unpaired lungs and gills (Cupello, Clément and Brito, 2019; Brito et al., 2010). Although some authors suggest that L. chalumnae fatty organ evidences a paired lung, previous studies proved that this organ is not the second lung, since there is no opened connection between this organ and the foregut or lung, nor lung plates surrounding it (Cupello et al., 2015; Cupello et al., 2017a; Cupello et al., 2017b). Based on these, the paired condition of coelacanth lungs can be excluded. 


\section{posterior $<---->$ anterior}

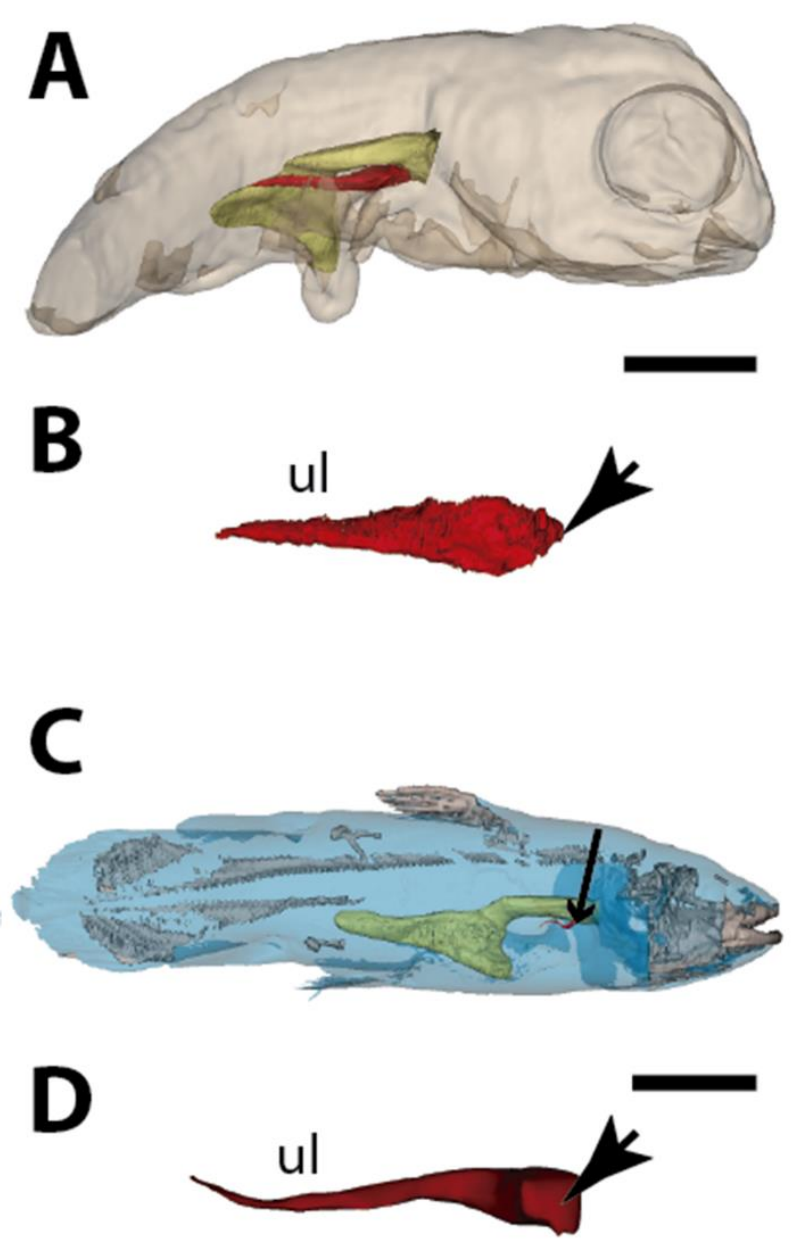

Fig. 3. Three-dimensional reconstructions of the pulmonary complex of Latimeria chalumnae. (A) Early embryo of Latimeria chalumane (45 $\mathrm{mm} \mathrm{TL}$ ) in right lateral view (Cupello et al., 2015), (B) Isolated unpaired lung of the early embryo in dorsal view, (C) Adult specimen of Latimeria chalumnae (1300 mm TL) in right lateral view (Cupello et al., 2015), (D) Isolated unpaired lung of the adult specimen in dorsal view. Yellow, foregut including the stomach; red, lung. Arrowheads in (B) and (D) pointing to the lung connection to the foregut. Black arrow in (C) pointing to the lung. Ul, unpaired lung bud in (B) and unpaired lung in (D). Scale bars, $5.0 \mathrm{~mm}$ (A); $5.0 \mathrm{~mm}$ (B); $200.0 \mathrm{~mm}$ (C); $40 \mathrm{~mm}$ (D). Modified from Cupello et al., 2015.

\section{The lung development in Neoceratodus forsteri}

The first developmental stage with lung anlage registered in this study is an early larva of $13.5 \mathrm{~mm}$ TL, with an unpaired morphology represented primarily by lung anterior projection (Fig. $4 \mathrm{~B}$ ). In larvae of $16 \mathrm{~mm}, 17 \mathrm{~mm}$, and $17.5 \mathrm{~mm}$ TL, although 
organogenesis is still not complete, a long and unpaired lung anlage is clearly identifiable

\section{The lung development in Lepidosiren paradoxa}

Lungs of the four specimens studied herein, from larva to adults (larva with $46 \mathrm{~mm}$ TL, juveniles with $68 \mathrm{~mm}$ TL and $222.1 \mathrm{~mm}$ TL, and adult with $400 \mathrm{~mm}$ TL), display a similar 
morphology and, surprisingly, left and right tubes do not arise simultaneously. Only the right sac is connected to the pharynx by a long pneumatic duct (Fig. 6 G, H, Fig. S4). The left sac is a branch of the right one, connected by a posterior and secondary opening at the lung level, already in dorsal position in relation to the foregut (Fig. 6 G, H, Fig. S4). There is no connection of the left sac with the pneumatic duct. In L. paradoxa, only the pneumatic duct is ventrally positioned, and the lung makes a complete dorsal turn up from the right side of the upper gastrointestinal tract (Fig. 4 F-K, Fig. S5), just after the ventral connection to the pharynx. This complete dorsal turn-up is also seen in the lung of adult specimens of $N$. forsteri (Fig. $4 \mathrm{I}-\mathrm{K}$ ). There are no anterior projections of the lung. Lung compartmentalization is clearly observable through dissections, evidencing the high degree of alveolation (Fig. S5). Our results indicate that the lung of L. paradoxa is, in fact, remarkably similar to $P$. senegalus lung. The so-called left lung of L. paradoxa is most likely a diverticulum or a modified lateral lobe, which had evolved secondarily, an advantage for enlarging the surface area for oxygen-uptake, eventually enabling the obligatory air-breathing performance in the linage towards L. paradoxa. 


\section{posterior <-----> anterior}
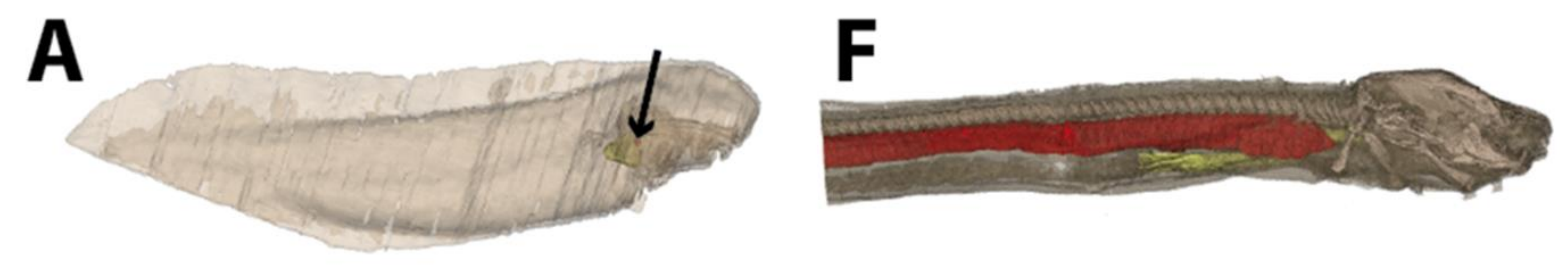

B
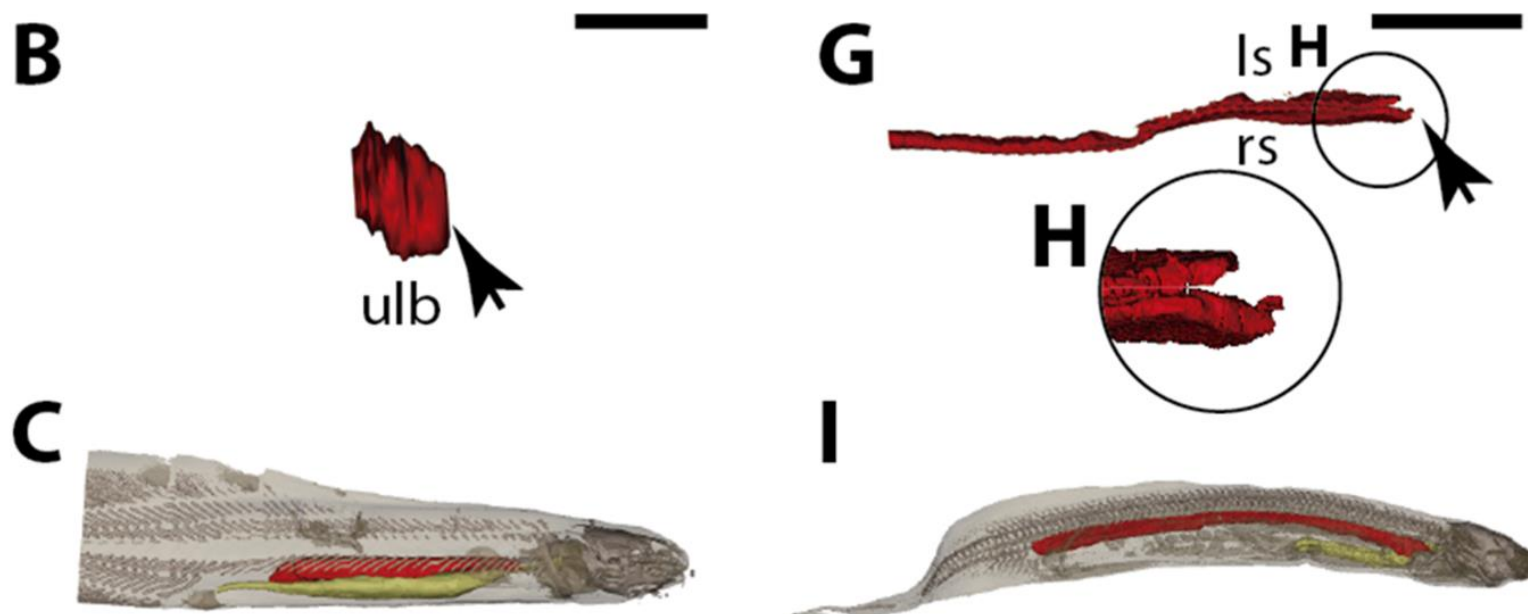

Fig. 4. Three-dimensional reconstructions of the pulmonary complex of two species of Lepidosirenoidea. (A) Early embryo of Neoceratodus forsteri (13.5 mm TL) in right lateral view, (B) Isolated unpaired lung of the early embryo in dorsal view, (C) Adult specimen of Neoceratodus forsteri (200 mm TL) in right lateral view, (D) Isolated unpaired lung of the adult specimen in dorsal view, (E) Close-up of the lung unpaired connection to the foregut in (D), (F) Larva of Lepidosiren paradoxa (46 mm TL) in lateral view, (G) Isolated lung of the larval specimen in dorsal view, (H) Close-up of the lung unpaired connection to the foregut in $(\mathrm{H}),(\mathbf{I})$ Juvenile of Lepidosiren paradoxa young adult (68 $\mathrm{mm}$ TL) in lateral view, (J) Isolated lung of the juvenile specimen in dorsal view, (K) Close-up of the lung unpaired connection to the foregut in $(\mathrm{J})$. Yellow, foregut including the stomach; red, lung. Black arrow in (A) pointing to the lung. Arrowheads in (B), pointing to the lung connection to the foregut and in $(\mathbf{D}),(\mathbf{G})$ and $(\mathbf{J})$ pointing the pneumatic duct connection to the foregut. Ls, left sac; rs, right sac; ul, unpaired lung; ulb, 
unpaired lung bud. Scale bars, $2.5 \mathrm{~mm}(\mathbf{A}) ; 0.1 \mathrm{~mm}(\mathbf{B}) ; 20 \mathrm{~mm}(\mathbf{C}) ; 10 \mathrm{~mm}$ (D, I, J); $5.0 \mathrm{~mm}(\mathbf{F}, \mathbf{G})$.

\section{The lung development in Salamandra salamandra}

In early larvae with $35.5 \mathrm{~mm}$ TL and $42.8 \mathrm{~mm}$ TL, paired lungs are collapsed in its middle and posterior portion (Fig. 5 A, B). The internal lung wall is thin and smooth, without compartmentalization and/or alveolation in its inner wall (Fig. 6 J, Fig. S6). From the early larvae onward, the muscular glottis develops on the ventral portion of the pharynx, and both left and right lungs arise simultaneously and symmetrically from a long trachea and paired first order bronchioles (Fig. 5 C, D, Fig. 6 I, J, Fig. S6). Lungs are symmetrical in size and morphology and are placed in the anteriormost portion of the abdominal cavity, as described for other tetrapods (Fig. 5 C, D). 


\section{posterior <----> anterior}

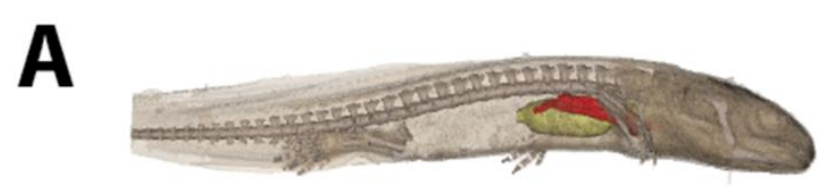

B
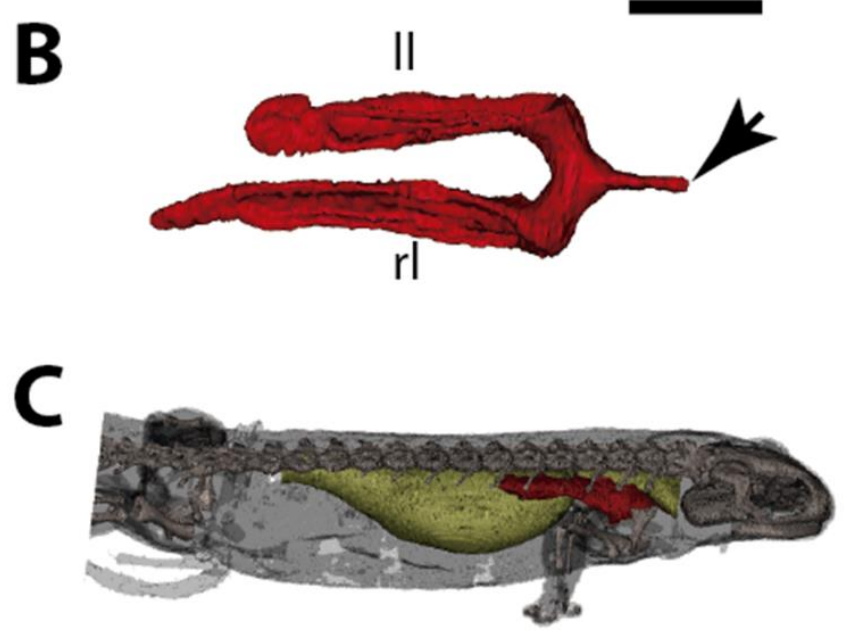

D

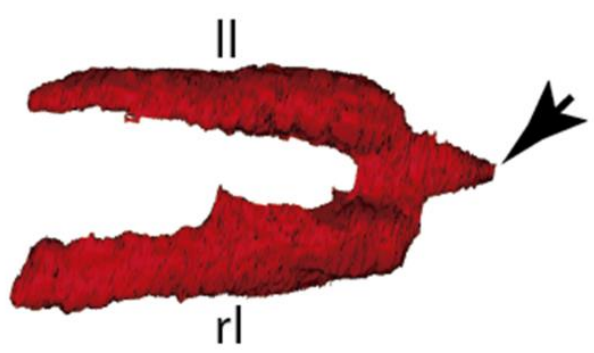

Fig. 5. Three-dimensional reconstructions of the pulmonary complex of Salamandra salamandra. (A) Early larva of Salamandra salamandra (35.5 $\mathrm{mm} \mathrm{TL})$ in right lateral view, (B) Isolated paired lung of the larva embryo in dorsal view, (C) Juvenile of Salamandra salamandra (81.85 mm TL) in right lateral view, (D) Isolated unpaired lung of the juvenile specimen in dorsal view. Yellow, foregut including the stomach; red, lung. Arrowheads in (B) and (D) pointing to the trachea connection to the foregut. Ll, left lung; rl, right lung. Scale bars, $5.0 \mathrm{~mm}$ (A); $3.125 \mathrm{~mm}$ (B); $10 \mathrm{~mm}$ (C); $6.25 \mathrm{~cm}$ (D).

In postmetamorphic juveniles (of $81.85 \mathrm{~mm} \mathrm{TL}$ ), paired lungs are already functional, not collapsed, and the main organ for oxygen-uptake (Goniakowska-Witalińska, 1978, 1982).

From this developmental stage onward, lungs are highly compartmentalized by multiple septa. Due to the paired and compartmentalized anatomy, the lung surface area for 
oxygen-uptake, as well as its volume capacity, increase substantially - both important features for a functional lung in dry environments. Here we confirm that at different developmental stages of $S$. salamandra, lungs are truly paired since both left and right lungs arise simultaneously and symmetrically and are directly connected to the trachea.

Throughout the ontogeny, S. salamandra lungs have a ventral origin, and makes a partial dorsal turn-up in its posterior portion, remaining parallel to the dorsal wall of the upper gastrointestinal tract. Due to the rarity of soft tissue preservation in the fossil record, only one species of salamandrid, Phosphotriton sigei presents its lung preserved (Tissier, Rage and Laurin, 2017). This lung is described as multichambered, placed in the anteriormost part of the abdominal cavity (Tissier, Rage and Laurin, 2017), such as in the living salamandrid described above. 
bioRxiv preprint doi: https://doi.org/10.1101/2022.02.14.480340; this version posted February 16, 2022. The copyright holder for this preprint (which was not certified by peer review) is the author/funder, who has granted bioRxiv a license to display the preprint in perpetuity. It is made available under aCC-BY 4.0 International license.
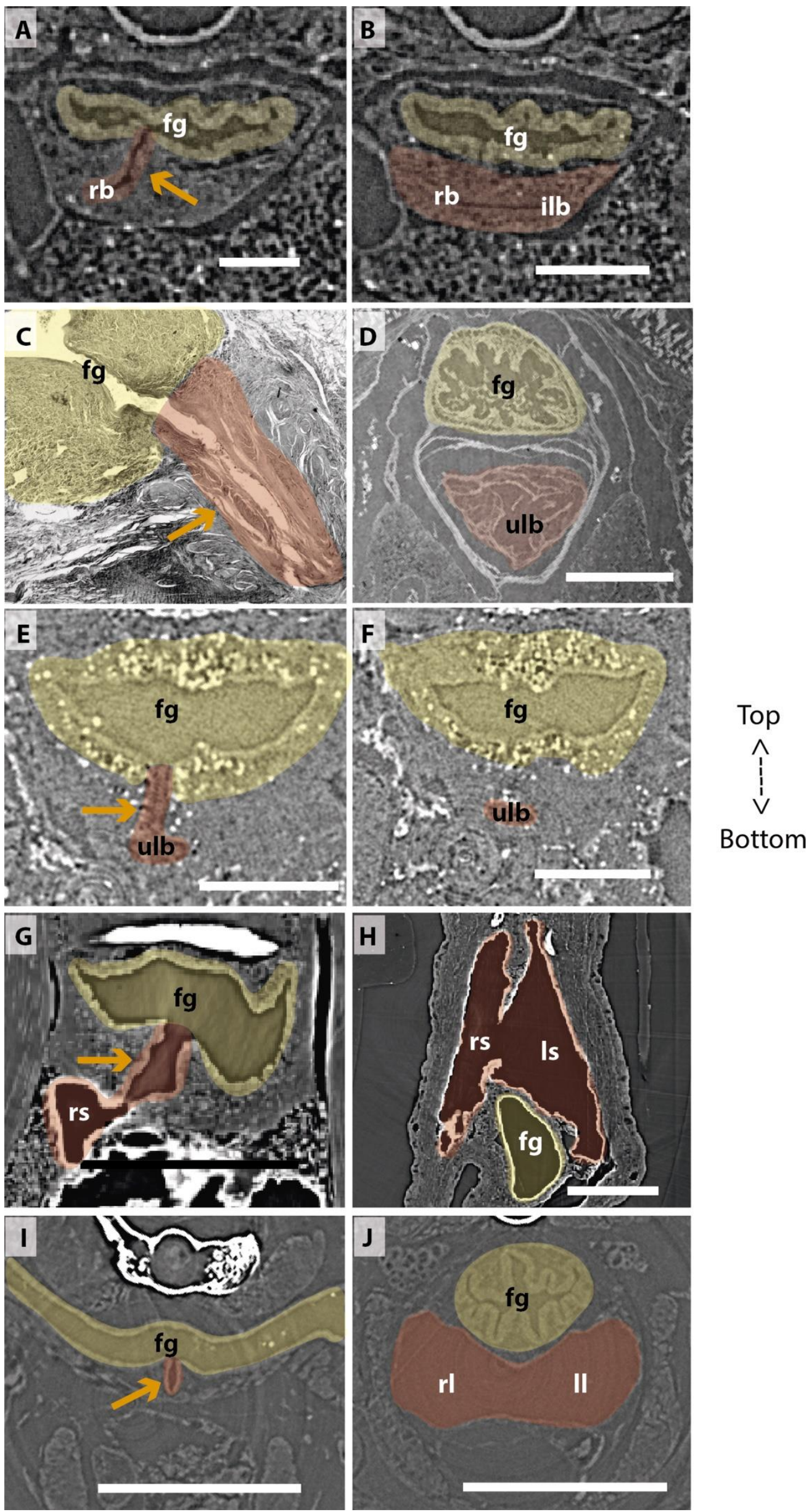


\section{Discussion}

Traditionally, vertebrate lungs are defined as ventral paired organs derived from the ventral portion of the posterior pharynx or post-pharyngeal foregut (Perry et al., 2001; Funk, Lencer and McCune, 2020; Lambertz and Perry, 2015; Graham, 1997; Kardong, 2015). However, we demonstrate here the presence of an unambiguous unpaired lung, that develop from the ventral foregut, but sometimes occupy the dorsal position later in the development of osteichthyan fishes (Fig. 7). Based on extensive developmental series of different vertebrate taxa, we present a new interpretation of some lungs previously considered as paired and, therefore, a new definition of paired lungs. Based on our results, true paired lungs are stated when bilateral lung buds arise simultaneously and are both connected directly to the foregut, as observed in the salamander (Fig. 7).

The sister group to all other living actinopterygian (polypterids) and all living sarcopterygian fishes have a clear unpaired lung in early developmental stages that can be developed in later stages either in a unilobed or a secondarily multilobed lung (Fig. 7), and not in a true paired lung. Polypterus senegalus and the lungfish L. paradoxa possess secondary multilobed structure from the larval stage onward since the lung is derived from 
a unilateral connection to the foregut. The presence of this secondary multilobed

morphology is an advantage for the obligatory air-breathing behavior of these taxa, raising

the respiratory compliance. In the teleost Batrachomoeus trispinosus, the non-respiratory

gas bladder is also described as paired (Rice and Bass, 2009), although it is certainly a secondary condition.

The most parsimonious scenario inferred from our data mapped on the phylogenetic framework (Fig. 7) is that the vertebrate lung was unpaired at the evolutionary origin.

Since soft tissue are rarely preserved in fossils, living lunged osteichthyans are key taxa for the understanding of how evolutionary constraints shaped breathing adaptations on land. Our study revealed that the ancestral condition of the lung is a median unpaired organ (Fig. 7), thereby being inconsistent with the scenario that the lung evolved through a modification of the posteriormost pharyngeal pouch assumed to be present in primitive taxa (Kastschenko, 1887; Goodrich, 1931). Consequently, the evolutionary origin of the lung was likely independent of the pharyngeal pouch at the morphological level.

From this evolutionary point of view, we complement lung definition as an unpaired or paired respiratory organ, or its vestigial form, that develops and are ventrally connected to the foregut. Some criteria previously used for discriminating lungs from gas bladders are no longer useful, including paired/unpaired organization, position ventral to the alimentary tract (Marcus, 1937; Funk, Lencer and McCune, 2020; Lambertz and Perry, 2015; Graham, 1997), as well as its function. The dorsal position of the majority of osteichthyans lungs described here may be related to its dual and secondary functionality of respiration and buoyancy control (Thomson, 1968). Actually, the only morphological characteristic that can be used to distinguish lungs and gas bladders is the ventral and dorsal origins from the foregut, respectively (Funk, Lencer and McCune, 2020; Cass, Servetnick and McCune, 2013). This phenotypic differentiation into true paired lungs in 
tetrapods may be related to differential gene expressions (Funk, Lencer and McCune, 2020; Bi et al., 2021). Nevertheless, at the developmental genetic level, the possibility of co-options of gene regulatory networks of the pharyngeal pouch morphogenesis cannot be excluded, as both the lung bud and pharyngeal pouch develop through the invagination of the foregut endoderm. Our results open the door for future molecular analyses to trace possible regulatory elements for the evolutionary transition from unpaired lungs to true paired lungs in tetrapods.

According to morphological evidence presented here, bifurcation morphogenesis into true paired lungs was not developed yet in osteichthyan fish ancestors. The bilaterally paired nature of the lung evolved only in the lineage towards the tetrapods, as a synapomorphy of this clade (Fig. 7). This morphological modification brought about improvement of the efficiency in oxygen-uptake from the air, as the paired lungs having parallel air flows exchange the air more quickly than the unpaired lung having only single air flow does. This innovation led to the elevation of metabolic rate that was required for the sustained body support against the gravity. Paired lungs may have been present also in early tetrapods and were probably essential to raise lung surface area and volume capacity during the evolution of vertebrate respiratory system and the air-breathing intensification at the water to land transition. 


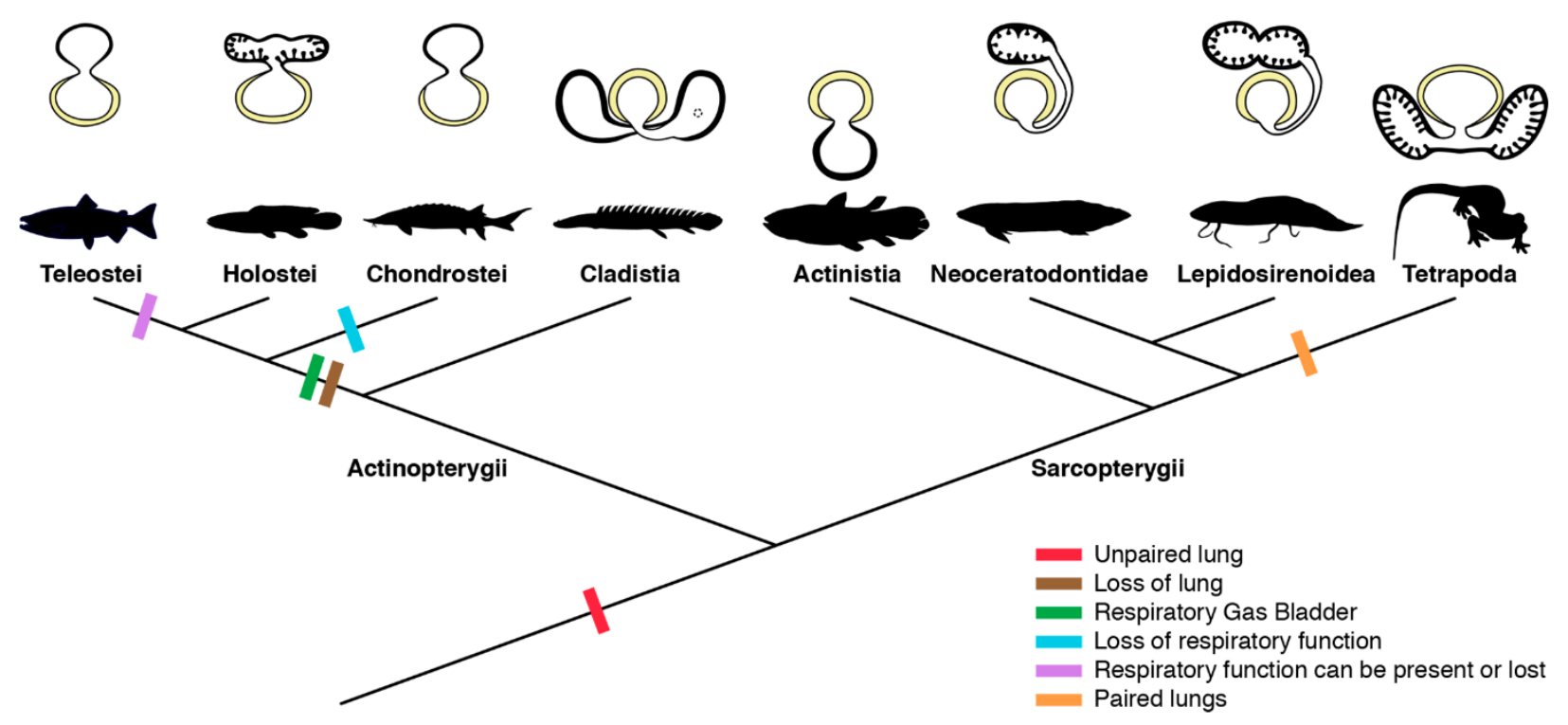

Fig. 7. Schematic figure reconstructing the evolutionary history of vertebrate lungs. All living actinopterygian and sarcopterygian fishes have unpaired lungs. True paired lungs are a synapomorphy of tetrapods. Dashed circle in Cladistia lung pointing to the secondary and independent opening to a left sac, at the lung level. Modified from Liem, 1988. This figure was made with free silhouettes from PhyloPic.

\section{Materials and Methods}

\section{Specimens information}

All specimens used in this work are permanently housed in collections of public institutions. No specimens were collected alive in the field for this work. Polypterus senegalus specimens were originally obtained for the study on the molecular developmental in polypterids (Tatsumi et al., 2016). Nine specimens here studied are: six late embryos (free embryonic phase or postembryos) of $8.0 \mathrm{~mm}$ TL (PS-001-01) and histological thin-section of another specimen of $8.0 \mathrm{~mm}$ TL (PSS-No1), $8.5 \mathrm{~mm}$ TL (PS001-02), 9.1 mm TL (PSS-No2) and 9.3 mm TL (two specimens, PS-001-03); four larva of $12 \mathrm{~mm}$ TL (two specimens, PS-001-04), $15.5 \mathrm{~mm}$ TL (PSS-No3) and 18.0 mm TL (PSS-No4); and three juveniles of $20 \mathrm{~mm}$ TL (PS-001-05), $23 \mathrm{~mm}$ TL (PS-001-06), and $45 \mathrm{~mm}$ TL (PS-001-07). We indicate the developmental stages (embryo, larvae, 
juveniles, and adults) following Bartsch, Gemballa and Piotrowski (1997). Specimens

and histological material are housed at the Department of Anatomy of the Jikei

University School of Medicine (Tokyo, Japan).

Four specimens of Lepidosiren paradoxa here studied are from the collections of the Universidade do Estado do Rio de Janeiro and were collected legally in 2008, with the permission number 11471-1. The specimens are registered under the acronym UERJ-

PN: UERJ-PN 550 is a larva of $46 \mathrm{~mm}$ TL; UERJ-PN 262 is a juvenile of $68 \mathrm{~mm}$ TL;

UERJ-PN 238 is juvenile of $222.1 \mathrm{~mm}$ TL; and PC02 is an adult of $400 \mathrm{~mm}$ TL. We follow Kerr (1900) for the developmental staging of Lepidosiren.

Specimens of Neoceratodus forsteri were collected legally from Department of Biological Sciences, Macquarie University, Sydney, Australia, and transported with the permission of CITES (Certificate No. 2009-AU-564836). The developmental series comprises fourteen specimens. Sizes are: an early embryo of $13.5 \mathrm{~mm}$ TL (IMU-RU-SI0013); 11 larvae of 16 mm TL (IMU-RU-SI-0017), 17 mm TL (IMU-RU-SI-0019 and IMU-RU-SI-0022], 17.5 mm TL (IMU-RU-SI-0037), 19 mm TL (IMU-RU-SI-0038), 20.5 mm TL (IMU-RU-SI-0039), 24 mm TL (IMU-RU-SI-0040), 25.5 mm TL (IMURU-SI-0041), 26.5 mm TL (IMU-RU-SI-0042), 30 mm TL (IMU-RU-SI-0043), and 50 mm TL (IMU-RU-SI-0045); a juvenile of 70 mm TL (IMU-RU-SI-0048); and an adult specimen of $200 \mathrm{~mm}$ TL (KPM-NI 11384). For the developmental identification (embryos, hatchlings/larvae, juveniles, and adults) we follow Kemp $(1982,2011)$ and Ziermann et al. (2018).

Six Salamandra salamandra specimens were obtained on loan at the amphibian collection of the Muséum national d'Histoire naturelle (Paris, France). The three developmental stages (as described at the MNHN collection) are: two early larvae MNHN 1978.636 (1) of $35.5 \mathrm{~mm}$ TL and MNHN 1978.636 (2) of $42.8 \mathrm{~mm}$ TL; larva 
MNHN 1985.9039 of 49.6 mm; larva in metamorphosis MNHN 1978.542 of 54.44 mm

TL; small juvenile MNHN 1988.7177 of 50 mm TL; juvenile MNHN 1962.1004 of

$81.85 \mathrm{~mm}$ TL.

Institutional abbreviations: IMU-RU-SI, Iwate Medical University, Ryozi Ura

Collection, Japan; PS, Polypterus senegalus; PSS, Polypterus senegalus sections; KPM-

NI, Kanagawa Prefectural Museum Natural History, Odawara, Japan; MNHN, Muséum

national d'Histoire naturelle, Paris, France; UERJ-PN, Universidade do Estado do Rio de Janeiro, Peixes Neotropicais.

\section{X-ray tomography}

Due to the extremely small size of the embryos and larvae, and to the weak density difference between soft tissues of the abdominal cavity, propagation phasecontrast microtomography was the unique way to study their anatomy and histology at micrometer scale. Phase-contrast microtomography being only achieved at synchrotron sources, we accessed the anatomy of these rare and tiny samples at the Synchrotron SOLEIL and Synchrotron SPring-8. The high brightness of the synchrotrons was essential for our material and enabled the collection high resolution scans in short timescales.

Specimens of P. senegalus, L. paradoxa and S. salamandra were imaged at the PSICHÉ beamline of the SOLEIL Synchrotron (Saint-Aubin, France) while N. forsteri specimens were scanned at SPring-8 Synchrotron. The specimens were scanned isolated in a plastic tube filled with Phosphate-buffered saline (PBS) for P. senegalus and N. forsteri, ethanol for L. paradoxa and formaldehyde for S. salamandra. They were immobilized in vertical position using gauze pads, and/or sank inside the tip of a plastic 
pipette in the case of tiny individuals, in order to benefit as much possible from the available field of view and thus achieve the highest possible resolution.

At SOLEIL Synchrotron, imaging was performed using a monochromatic beam with an energy of $25 \mathrm{keV}$. A series of acquisitions with vertical movement of the sample were recorded to extend vertically the field of view and image the entire (or most of the) individual. Two distinct setups were used to accommodate the different sizes of the individuals (size variations occurring both between developmental stages and taxa). (1) Small individuals were scanned using a field of view of $2.6 \times 2.6 \mathrm{~mm}^{2}(5 \mathrm{x}$ magnification) resulting in a projected pixel size of $1.3 \mu \mathrm{m}$, and a propagation distance of $148 \mathrm{~mm}$. (2) Larger individuals were scanned using a field of view of $\sim 12.6 \times 3.3 \mathrm{~mm}^{2}$ (1x magnification) resulting in a projected pixel size of $6.17 \mu \mathrm{m}$, and a propagation distance of $500 \mathrm{~mm}$. For individuals slightly wider than these field of views, the latter were extended horizontally by positioning the rotation axis off-centre and acquiring data over a $360^{\circ}$ rotation of the sample. The volumes were reconstructed from the (vertically) combined radiographs using PyHST2 software (Mirone et al., 2014), with a Paganin phase retrieval algorithm (Paganin et al., 2002). The huge resulting volumes (from $70 \mathrm{~Gb}$ to $1.2 \mathrm{~Tb}$ ) were reduced (crop, rescale 8-bit, binning) to facilitate 3D data processing. Specimens of Neoceratodus forsteri (from 13.5 to $70 \mathrm{~mm}$ TL) were imaged at the SPring-8 Synchrotron, beamline 20B2. For specimens from $13.5 \mathrm{~mm}$ TL to $30 \mathrm{~mm}$ TL, a beam energy of $15 \mathrm{keV}$ was used with a double bounce Si (111) monochromator. Data were obtained at three different resolutions, and correspondingly used three combinations of two lenses and fluorescent material, as follows, $2.75 \mu \mathrm{m} / \mathrm{voxel}$; $1 \mathrm{st}-$ stage lens: "beam monitor 2" f35 mm; 2nd-stage lens: Nikon 85 mm lens; GADOX thickness: $15 \mu \mathrm{m} 4.47 \mu \mathrm{m} /$ voxel; 1st-stage lens: "beam monitor 2" f35 mm; 2nd-stage lens: Nikon 50 mm lens; GADOX thickness: $15 \mu \mathrm{m} 12.56 \mu \mathrm{m} /$ voxel; 1st-stage lens: 
"beam monitor 5" f200 mm; 2nd-stage lens: Nikon 105 mm lens; GADOX thickness: 25 $\mu \mathrm{m}$.

\section{Segmentation and three-dimensional rendering}

Segmentation and 3D rendering were performed using the software MIMICS Innovation Suite 20.0 (Materialise) at the Laboratório de Ictiologia Tempo e Espaço of the Universidade do Estado do Rio de Janeiro.

\section{References}

1. Amemiya, C. T.; Alföldi, J.; Lee, A. P.; Fan, S.; Philippe, H.; MacCallum, I...., Lindblad-Toh, K. The African coelacanth genome provides insights into tetrapod evolution. Nature 496, 311-316 (2013).

2. Bartsch, P.; Gemballa, S.; Piotrowski, T. The Embryonic and Larval Development of Polypterus senegalus Cuvier, 1829: its Staging with Reference to External and 
Skeletal Features, Behaviour and Locomotory Habits. Acta Zool. 78, 309-328

(1997).

3. Bi, X.; Wang, K.; Yang, L.; Pan, H.; Jiang, H.; Wei, Q...., Zhang, G. Tracing the genetic footprints of vertebrate landing in non-teleost ray-finned fishes. Cell 184, 1377-1391 (2021).

4. Brito, P. M.; Meunier, F. J.; Clément, G.; Geffard-Kuriyama, D. The histological structure of the calcified lung of the fossil coelacanth Axelrodichthys araripensis (Actinistia: Mawsoniidae). Palaeontology 53, 1281-1290 (2010).

5. Cass, A. N.; Servetnick, M. D.; McCune, A. R. Expression of a lung developmental cassette in the adult and developing zebrafish swimbladder. Evol Dev 15, 119-132 (2013).

6. Cupello, C.; Brito, P. M.; Herbin, M.; Meunier, F. J.; Janvier, P.; Dutel, H.; Clément, G. Allometric growth in the extant coelacanth lung during ontogenetic development. Nat. Commun. 6, 8222 (2015).

7. Cupello, C.; Meunier, F. J.; Herbin, M.; Clément, G.; Brito, P. M. Lung anatomy and histology of the extant coelacanth shed light on the loss of air-breathing during deep-water adaptation in actinistians. Roy. Soc. Open Sci. 4, 161030 (2017a).

8. Cupello, C.; Meunier, F. J.; Herbin, M.; Janvier, P.; Clément, G.; Brito, P. M. The homology and function of the lung plates in extant and fossil coelacanths. Sci. Rep. 7, 1-8 (2017b)

9. Cupello, C.; Clément, G.; Brito, P. M. in Evolution and Development of Fishes (Cambridge University Press, Cambridge, 2019), pp. 252-262.

10. Funk, E.; Lencer, E.; McCune, A. Dorsoventral inversion of the air-filled organ (lungs, gas bladder) in vertebrates: RNAsequencing of laser capture microdissected embryonic tissue. J. Exp. Zool. Part. B. 334, 325-338 (2020). 
11. Geoffrey Saint Hilaire, E. Histoire naturelle et description anatomique d'un nouveau genre de poisson du Nil, nommé Polyptére. Paris Mus. Nat. Hist. Ann. 1, 57-68 (1802).

12. Goniakowska-Witalińska, L. Ultrastructural and morphometric study of the lung of the European salamander, Salamandra salamandra L. Cell and Tissue Res. 191, 343356 (1978).

13. Goniakowska-Witalińska, L. Development of the larval lung of Salamandra salamandra L. Anat. Embryol. 164, 113-137 (1982).

14. Goodrich, E. S. Studies on the Structure and Development of Vertebrates. J. N. Ment. Dis. 74, 678 (1931).

15. Goujet, D. "Lungs" in placoderms, a persistent palaeobiological myth related to environmental preconceived interpretations. C. R. Palevol. 10, 323-329 (2011).

16. Graham, J. B. Air breathing fishes: evolution, diversity and adaptation (Academic Press, 1997).

17. Greil, A. Entwickelungsgeschichte des Kopfes und des Blutgefäßsystems von Ceratodus forsteri. II. Die epigenetischen Erwerbungen während der Stadien 39-48. Denkschr. Med. Naturwiss. Ges. Jena. 4, 935-1492 (1913).

18. Grigg, G. C. Studies on the Queensland lungfish, Neoceratodus forsteri (Krefft). 1. Anatomy, histology, and functioning of the lung. Aust. J. Zool. 13, 243-253 (1965).

19. Icardo, J. M.; Colvee, E.; Kuciel, M.; Lauriano, E. R.; Zaccone, G. The lungs of Polypterus senegalus and Erpetoichthys calabaricus: insights into the structure and functional distribution of the pulmonary epithelial cells. J. Morphol. 278, 1321-1332 (2017).

20. Kardong, K. V. The respiratory system, Vertebrates: Comparative anatomy, function, evolution, 413-450 (2015). 
21. Kastschenko, N. Das Schlundspaltengebiet des Hühnchens. Arch. Anat. Phys. Anat. Abt. 258-300 (1887).

22. Kemp, A. The embryological development of the Queensland lungfish, Neoceratodus forsteri (Krefft). Mem. Qd. Mus. 20: 553-97 (1982).

23. Kemp, A. The biology of the Australian lungfish, Neoceratodus forsteri (Krefft 1870). J. Morphol. 190, 181-198 (1986).

24. Kemp, A. Comparison of embryological development in the threatened Australian lungfish Neoceratodus forsteri from two sites in a Queensland river system. Endanger Species Res. 15, 87-101 (2011).

25. Kerr, S. G. V. The external features the development of Lepidosiren paradoxa, Fitz. Philos. Tr. R. Soc. Lon. B, 192, 299-330 (1900).

26. Kuratani, S.; Tanaka, S. Peripheral development of the avian vagus nerve with special reference to the morphological innervation of heart and lung. Anat. Embryol. 182, 435-445 (1990).

27. Lambertz, M.; Grommes, K.; Kohlsdorf, T.; Perry, S. F. Lungs of the first amniotes: why simple if they can be complex? Biol. Lett. 11, 20140848 (2015).

28. Lambertz, M.; Perry, S. F. in Phylogeny, Anatomy and Physiology of Ancient Fishes, (CRC Press, Florida, 2015), pp. 201-211.

29. Liem, K. Form and function of lungs: the evolution of air breathing mechanisms. Amer. Zool. 28, 739-759 (1988).

30. Marcus, H. in: Lunge, Handbuch der vergleichenden Anatomie der Wirbeltiere (Urban and Schwarzenberg, Berlin, 1937).

31. Marshall Flint, J. The development of the lungs. Am. J. Anat. 6, 1-137 (1906).

32. Mirone, A.; Gouillart, E.; Brun, E.; Tafforeau, P.; Kieffer, J. The PyHST2 hybrid distributed code for high speed tomographic reconstruction with iterative 
reconstruction and a priori knowledge capabilities. Nucl. Instrum. Methods 324, 41-

48 (2014).

33. Neumayer, L. Die Entwicklung des Darmkanales, von Lunge, Leber, Milz und Pankreas bei Ceratodus. Forsteri. Zool. Forsch. reisen 1, 379-422 (1904).

34. Neumayer, L. Die Entwicklung des Darms von Acipenser. Acta Zool. 39, 1-151 (1930)

35. Paganin, D.; Mayo, S. C.; Gureyev, T. E.; Miller, P. R.; Wilkins, S. W. Simultaneous phase and amplitude extraction from a single defocused image of a homogeneous object. J. Microsc. 206, 33-40 (2002).

36. Perry, S. F.; Wilson, R. J. A.; Straus, C.; Harris, M. B.; Remmers, J. E. Which came first, the lung or the breath? Comp. Biochem. and Physiol. 129, 37-47 (2001).

37. Pierce, S. E.; Lamas, L. P.; Pelligand, L.; Schilling, N.; Hutchinson, J. R. Patterns of limb and epaxial muscle activity during walking in the fire salamander, Salamandra salamandra. Integr. Org. Biol. 2, obaa015 (2020).

38. Rice, A. N.; Bass, A. H. Novel vocal repertoire and paired swimbladders of the three-spined toadfish, Batrachomoeus trispinosus: insights into the diversity of the Batrachoididae. J. Exp. Biol. 1377-1391 (2009).

39. Spencer, W. B. Contributions to Our Knowledge of Ceratodus: The Blood Vessels. Linnean Soc of New South Wales (1893).

40. Tatsumi, N.; Kobayashi, R.; Yano, T.; Noda, M.; Fujimura, K.; Okada, N.; Okabe, M. Molecular developmental mechanism in polypterid fish provides insight into the origin of vertebrate lungs. Sci. Rep. 6, 30580 (2016).

41. Thomson, K. S. Lung ventilation in dipnoan fishes. Pea. Mus. Nat. Hist. 122, 1-6 (1968). 
42. Tissier, J.; Rage, J-C.; Laurin, M. Exceptional soft tissues preservation in a mummified frog-eating Eocene salamander. PeerJ 5: e3861 (2017).

43. Wassnetzov, W. Über die Morphologie der Schwimmblase. Zool. Jahrb. Allg. Zool. 56, 1-36 (1932).

44. Ziermann, J. M.; Clement, A. M.; Ericsson, R.; Olsson, L. Cephalic muscle development in the Australian lungfish, Neoceratodus forsteri. J. Morphol. 279, 494516 (2018).

\section{Acknowledgments}

We thank J. Joss (Macquarie University) for providing Neoceratodus embryos. We are grateful to Dr H. Seno (curator of the Ichthyology Collection of the Kanagawa Prefectural Museum of Natural History) for the loan of Neoceratodus specimen KPM-NI 11384.

\section{Funding:}

Coordenação de Aperfeiçoamento de Pessoal de Nível Superior-Brasil (CAPES)—grant Finance Code 001 (Programa Nacional de Pós Doutorado-PNPD) (CC)

Programa de Apoio à Docência (PAPD) grant E-26/007/10661/2019)_Universidade do

Estado do Rio de Janeiro (CC)

Interdisciplinary Collaborative Research Program of the Atmosphere and Ocean Research Institute, the University of Tokyo JP (CC, TS)

Prociência fellowship CNPq grant 310101/2017-4 (PMB) 


\section{Author contributions:}

Examples:

Conceptualization: CC, YY, PMB

Synchrotron acquisitions: CC, TH, YY, PG, SI, AK, MH, KU, PMB

CT scan acquisitions: RM

Computerized microtomography rendering: CC, NT

Histological thin sections preparation: NT, MO

Specimens dissection: CC, NT, SI

Figures: CC, PG

Data interpretation and Writing — original draft: CC, TH, NT, YY, PG, MO, PMB

AK, MH, KU, MO, PMB

Competing interests: All authors declare no competing interests.

Data and materials availability: All data are available in the main text or the supplementary materials.

\section{Supplementary Materials}


bioRxiv preprint doi: https://doi.org/10.1101/2022.02.14.480340; this version posted February 16, 2022. The copyright holder for this preprint (which was not certified by peer review) is the author/funder, who has granted bioRxiv a license to display the preprint in perpetuity. It is made available under aCC-BY 4.0 International license.

Supplementary information is available for this paper at https://doi.org/. 


\title{
Supplementary Information for
}

\section{Lung evolution in vertebrates and the water-to-land transition}

\author{
Camila Cupello, ${ }^{1 *}$ Tatsuya Hirasawa, ${ }^{2}$ Norifumi Tatsumi, ${ }^{3}$ Yoshitaka Yabumoto, ${ }^{4}$ Pierre \\ Gueriau, ${ }^{5,6}$ Sumio Isogai, ${ }^{7}$ Ryoko Matsumoto, ${ }^{8}$ Toshiro Saruwatari, ${ }^{9,10}$ Andrew King, ${ }^{11}$ \\ Masato Hoshino, ${ }^{12}$ Kentaro Uesugi, ${ }^{12}$ Masataka Okabe, ${ }^{3}$ Paulo M. Brito ${ }^{1 *}$
}

*Corresponding authors. Email: camila.dc@gmail.com; pbritopaleo@yahoo.com.br

\section{This PDF file includes:}

Figs. S1 to S5 
bioRxiv preprint doi: https://doi.org/10.1101/2022.02.14.480340; this version posted February 16, 2022. The copyright holder for this preprint (which was not certified by peer review) is the author/funder, who has granted bioRxiv a license to display the preprint in perpetuity. It is made available under aCC-BY 4.0 International license.

Fig. S1. Sections of synchrotron X-ray microtomography of a juvenile of Polypterus senegalus (23 mm TL). (A) Unpaired lung origin. (B) Right sac arising from the foregut. (C) Left sac arising from an independent and lateral connection to the right sac. (D) Right and left sacs. Yellow, foregut; red, lung. Orange arrow, opened connection between foregut and lung. Fg, foregut; ls, left sac; rs, right sac. Scale bars, $0.5 \mathrm{~mm}$ (A-D).
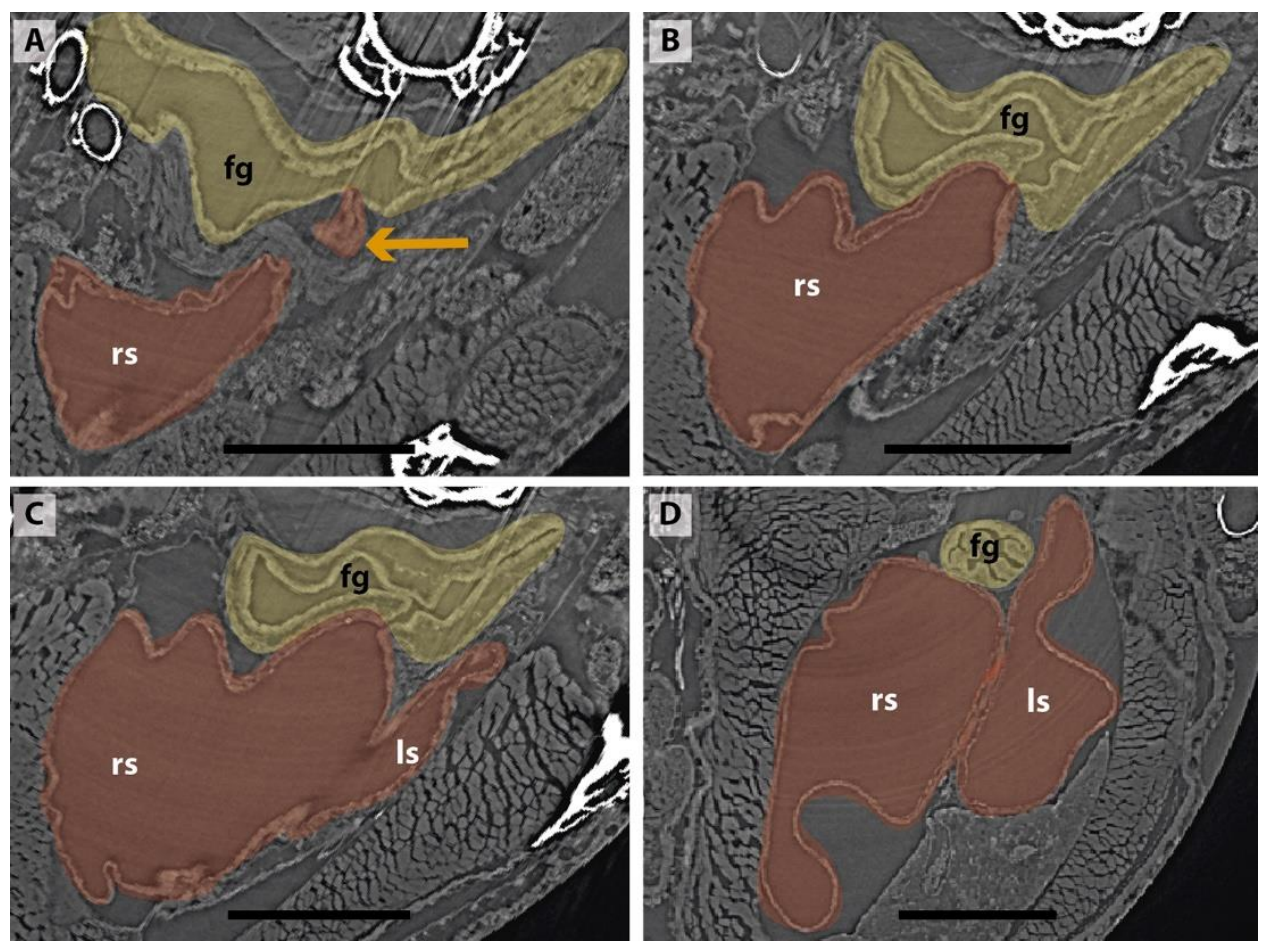
Fig. S2. Three-dimensional reconstructions of the pulmonary complex of Polypterus senegalus. (A) Virtual section of the juvenile (45 $\mathrm{mm}$ TL) in anterior view, evidencing the oesophagus and the lung in 3D. (B) Isolated right lung of the juvenile in lateral view, evidencing the independent and secondary connection of the left sac to the right one by a lateral opening. Yellow, foregut including the stomach; red, right sac; blue, left sac, dashed line, independent and secondary connection of the left sac to the right one.
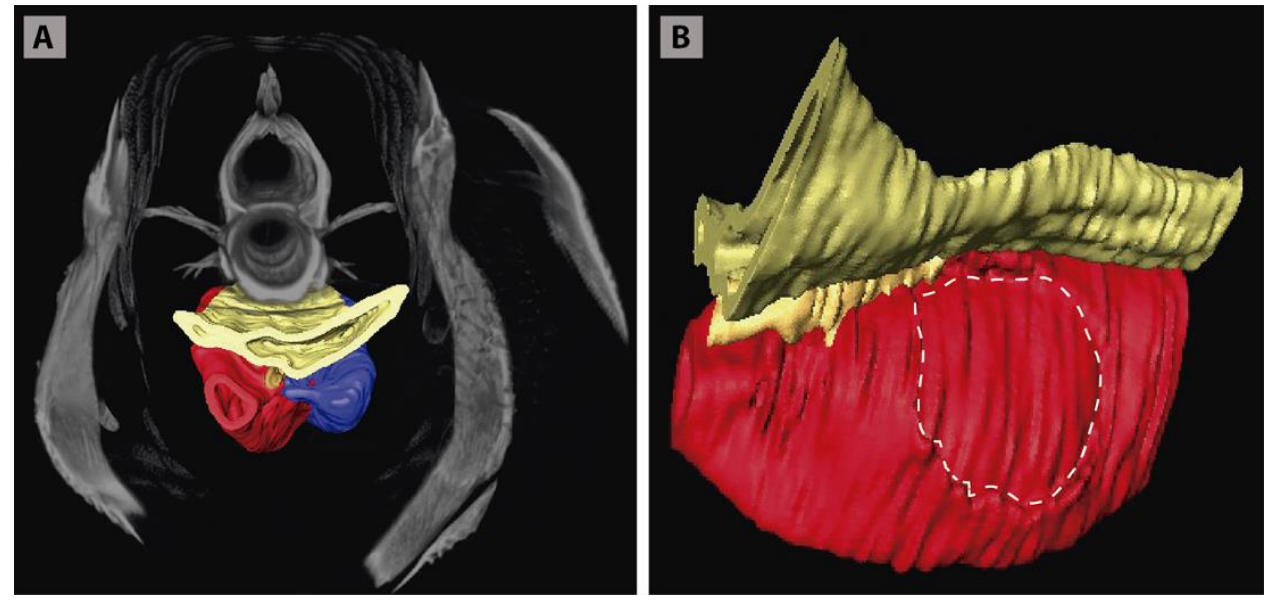
bioRxiv preprint doi: https://doi.org/10.1101/2022.02 14.480340; this version posted February 16, 2022. The copyright holder for this preprint (which was not certified by peer review) is the author/funder, who has granted bioRxiv a license to display the preprint in perpetuity. It is made available under aCC-BY 4.0 International license.

Fig. S3. Sections of synchrotron X-ray microtomography of a larva of Neoceratodus forsteri $(19 \mathrm{~mm}$ TL). (A) Unpaired lung origin. (B) Unique sac arising from the foregut. (C, D) Unique sac developing. Yellow, foregut; red, lung. Orange arrow, opened connection between foregut and lung. fg, foregut; us, unique sac. Scale bars, $0.5 \mathrm{~mm}$ (A-D).
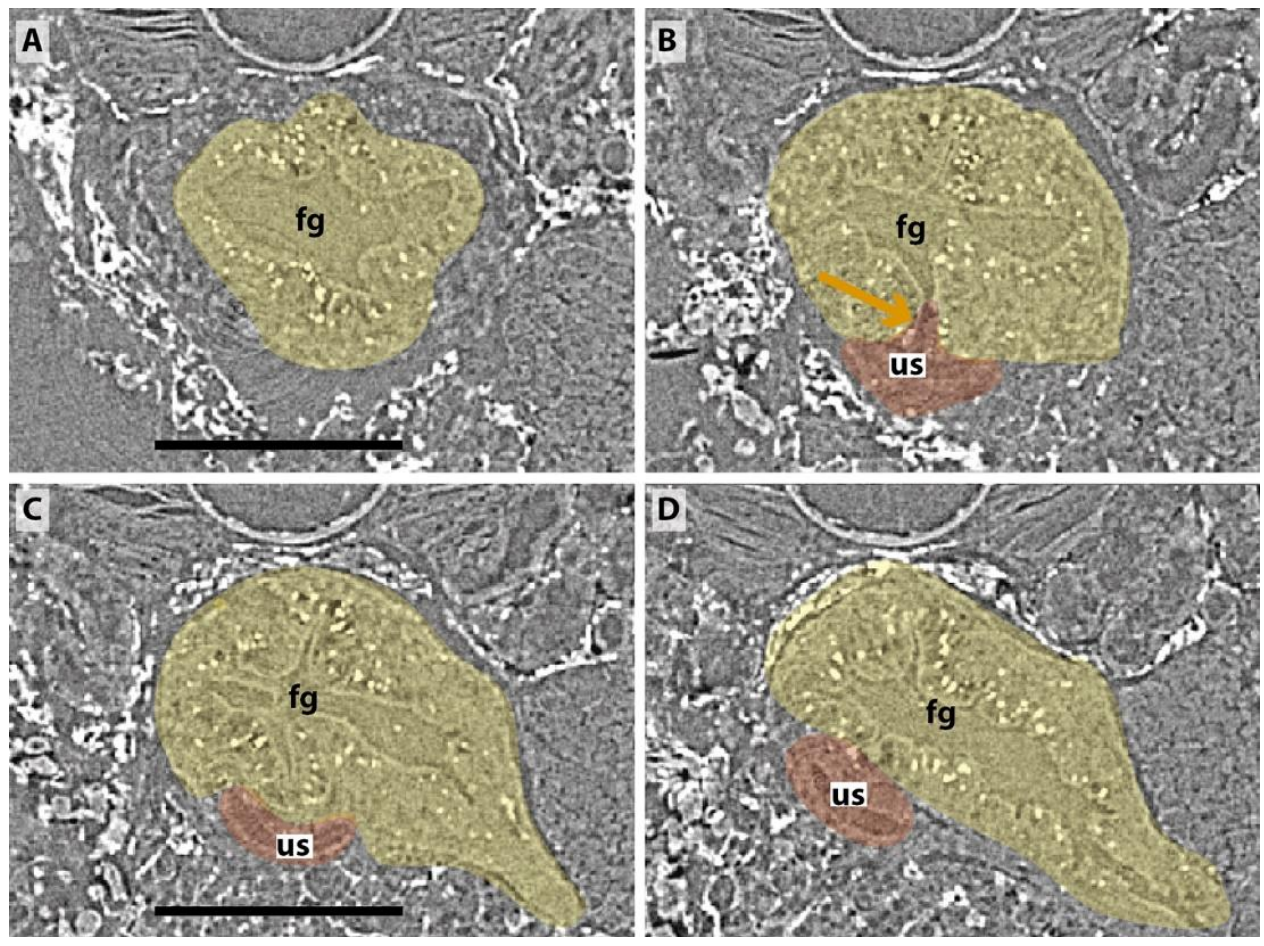
Fig. S4. Sections of synchrotron X-ray microtomography of a juvenile of Lepidosiren paradoxa (68 mm TL). (A) Unpaired lung origin. (B) Right sac arising from the foregut. (C) Left sac arising from an independent and lateral connection to the right sac. (D) Right and left sacs. Yellow, foregut; red, lung. Orange arrow, opened connection between foregut and lung. fg, foregut; ls, left sac; rs, right sac. Scale bars, $0.5 \mathrm{~mm}$ (A-D).
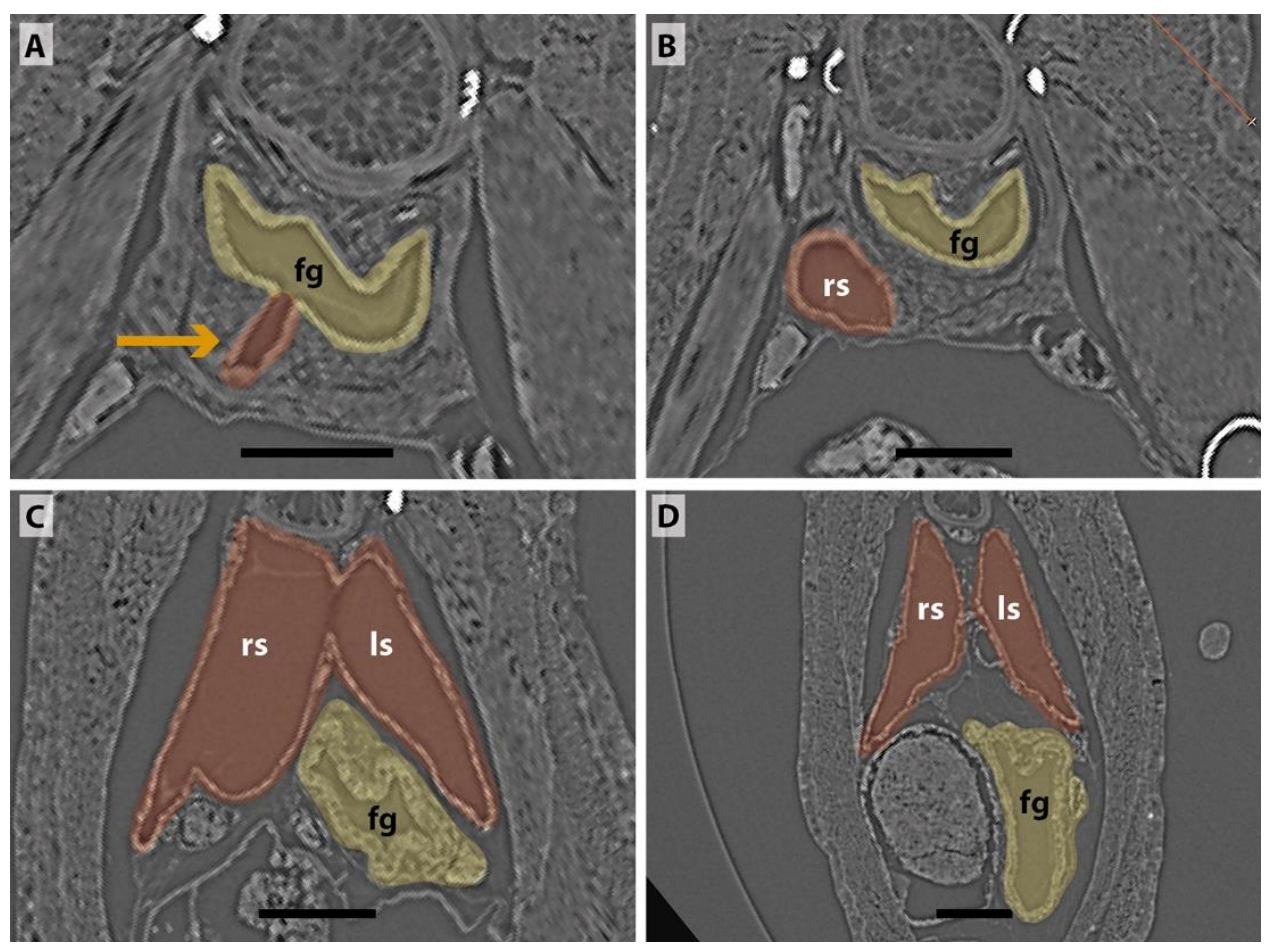
bioRxiv preprint doi: https://doi.org/10.1101/2022 02.14 .480340 ; this version posted February 16,2022 . The copyright holder for this preprint (which was not certified by peer review) is the author/funder, who has granted bioRxiv a license to display the preprint in perpetuity. It is made available under aCC-BY 4.0 International license.

Fig. S5. Dissection of the lung of an adult Lepidosiren paradoxa (400 $\mathrm{mm}$ TL). Red arrow, lung. Black arrow, ventral insertion of the right sac. ls, left sac; rs, right sac. Scale bars, $50 \mathrm{~mm}$ (A, B); $10 \mathrm{~mm}(\mathbf{C})$.
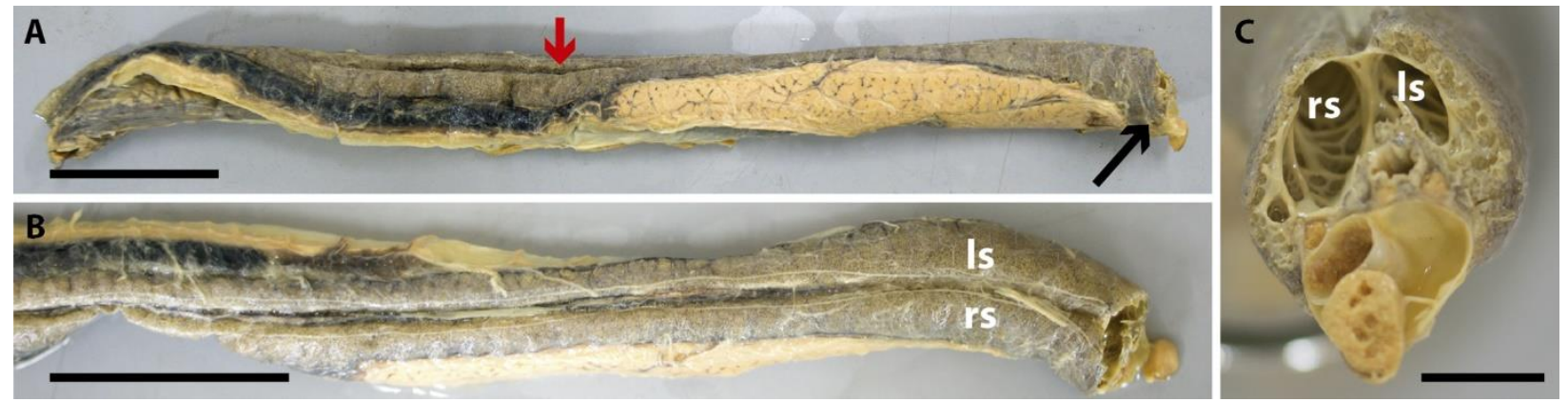
Fig. S6. Sections of synchrotron X-ray microtomography of a larva of Salamandra salamandra (42.8 mm TL). (A, B) Trachea arising. (C, D) Fist order bronchioles. (E) Right and left lungs arising simultaneously and symmetrically. Yellow, foregut; red, lung. Orange arrow, opened connection from the foregut. br, braonchile; fg, foregut; ll, left lung; rl, right lung; tr, trachea. Scale bars, $0.5 \mathrm{~mm}$ (A-D).
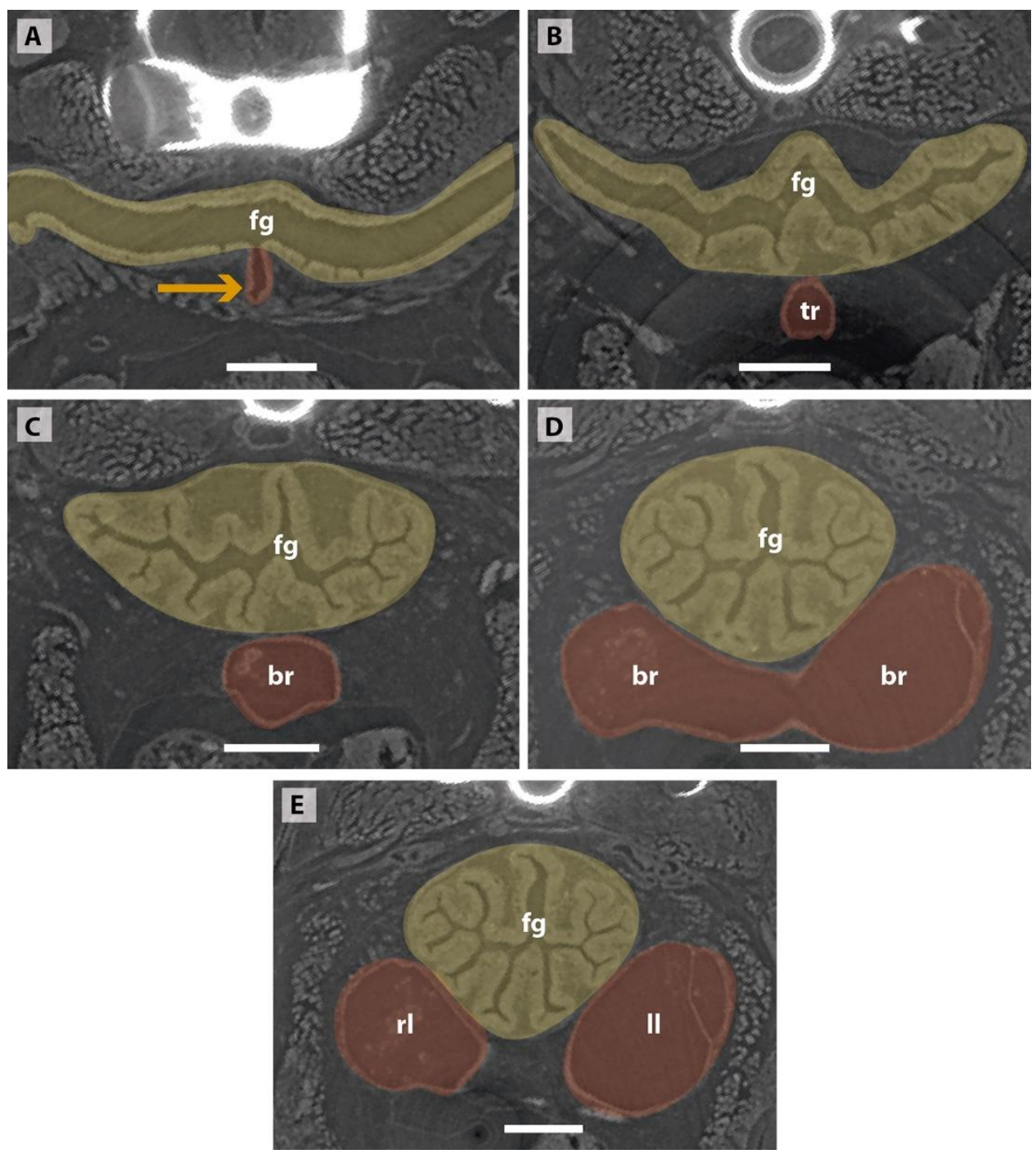